\title{
Development of Adaptive Mobile Learning (AML) on Information System Courses
}

\author{
I Made Agus Wirawan ${ }^{1}$ \\ Department of Informatics Technology Education, \\ Faculty of Engineering and Vocational, \\ Ganesha University of Education, Bali, Indonesia
}

\author{
Made Santo Gitakarna ${ }^{2}$ \\ Department of Electronics Technnics Education, \\ Faculty of Engineering and Vocational, \\ Ganesha University of Education
}

\begin{abstract}
In general, the learning process is done conventionally, where the learning process is done face to face between teachers with learners in the classroom. Teachers have a very important role in determining the quantity and quality of the implementation study. Therefore, teachers must think and plan carefully to improve learning opportunities for learners and improve the quality of teaching. Along with the development of mobile technology and communication is rapidly increasing, enabling the learning process is not only done in the classroom, but can be done anywhere and anytime. Based on the analysis of the results of observations in the class conducted by a researcher and as a teacher in the learning courses of Information Systems, found some obstacles encountered during the learning process

This research is to develop an Adaptive Mobile Learning on Information Systems courses. The method used in this research is the development of research methods (research and development), which selected the design development using System Development Life Cycle model. Adaptive Mobile Learning will be validated and tested through three phases of testing are: (1) Product technical test as a software. (2) Testing of the product as a medium of learning, through expert review by a media expert, (3) Field test to evaluate the response of the students that learned Adaptive Mobile Learning.

The results show that Adaptive Mobile Learning software is can present the material in the course of Information Systems. Media Adaptive Mobile Learning can be used as an alternative medium (supplement) of learning Information Systems courses. The response of students to the development and use of software for Adaptive Mobile Learning Information Systems courses is likely to very positive, which is at $67.7 \%$ very positive and $32.3 \%$ is positive.
\end{abstract}

Keywords-Mobile Learning; Information System Course; Learning Media; Adaptive Learning; Learners Response; Research and Development

\section{INTRODUCTION}

In general, the learning process is done conventionally, where the learning process is done face to face between teachers with learners in the classroom. Teachers have a very important role in determining the quantity and quality of the implementation study. Therefore, teachers must think and plan carefully to improve learning opportunities for learners and improve the quality of teaching. Along with the development of mobile technology and communication is rapidly increasing, enabling the learning process is not only done in the classroom, but can be done anywhere and anytime.

Based on the analysis of the results of observations in the class conducted by a researcher and as a teacher in the learning courses of Information Systems, found some obstacles encountered during the learning process, such: 1) Students are less active in taking the time to learn the material outside of class Information Systems. That is because the learning tools that are used less flexible. 2) The less effective learning process in the Department of Informatics Technology Education especially on Information System course, caused by some national holidays and religious holidays. 3) The learning process is given by the lecturer in the classroom of a general nature, which is considered the same level of students ability by lecturers. E-Learning can be viewed as an innovative approach for delivering well-designed, learner-centered, interactive, and facilitated learning environment to anyone, anyplace, anytime by utilizing the attributes and resources of various digital technologies along with other forms of learning materials suited for open, flexible, and distributed learning environment" [1]. However, eLearning courses have witnessed high drop out rates as learners become increasingly dissatisfied with courses that do not engage them [2]; [3].

Each student has a different cognitive abilities [4]. In [5]; [6]; [7]; [8]; [9] those problems can be overcome with the use of adaptive learning system. Many studies have been conducted on adaptive learning. Among them, studies that provide the most universal method of adaptability offer courseware by considering learner styles [10]; [11]; [12]; [13]; [14]; [15]; [16]. However, there are also theories that assert that a learning strategy created according to either a task or content is much more effective than the learning style [17]; [18]; [19]. It is thus necessary to provide adaptability according to the learning content along with the learning style.

In [20] the previous study researchers have developed a smartphone application on the SQL Advanced Database for the same student. This material is still static, and the system was not able to present the material by the ability level of each learner.

Based on the description of the problem and the other researches, researchers looked at the need for the development of Adaptive Mobile Learning (AML) to support the learning process of Information Systems. This research is the development of technology-based adaptive learning media on Information Systems material. Application of this smartphone can be used as a supplement in the learning process of Information System. 


\section{LITERATURE REVIEW}

\section{A. Introduction of Adaptive Learning}

Adaptive Learning based on constructivist theory and the theory of cognitive flexibility. Adaptive learning is a specific way of learning in the process of solving a particular problem, learners acquire knowledge and skills through positive thinking and operating. Adaptive learning is active learning. Learners can monitor their own learning process, and choose the most appropriate learning content to their actual needs [21].

\section{B. Features of Adaptive Learning}

The rapid development of the Internet and new technologies, which are related to the distance learning system in the network environment has been greatly advanced. Adaptive learning system emerged in response to the characteristics of learners. The above systems have common features as follows [21]:

1) A personalized learning system with the learner as the main body. In accordance with the learning needs, abilities and learning styles of learners. The system actively adjusts the learning content, learning styles, learning strategies, learning flow and learning support, and present learning materials in accordance with the level of ability of learners, whole learning process centered on the learner to meet the learning process of students, in which the dominant position of learners if fully realized.

2) The self-construction of knowledge. Learners are actively interacting with adaptive learning system and analyzing feedback information, which aims to build up their knowledge. By recording system adaptive learning of the learning process, learners can control with timely and adjust their own learning process to achieve the learning objectives required.

3) The adaptive learning system is intelligent. Intelligence is a basic guarantee for the adaptation of the system to realize independently. This allows the system comprehensively in diagnosing the extent and actual psychological condition of students. So that the learning content is presented and learning support in accordance with the pretest and tracking the learning process.

\section{Learner Profile}

In adaptive system, learner profile components use to obtain student information. This information is stored without making changes, and does not close the possibility of changing information. Changes occur because learner profiles information such as: level of motivation, learning style, and others also change. The learner profile has four categories of information that can be used as benchmarks, namely: [15].

1) Studen's behavior, consists of information: level of motivation, learning style and learning materials.

2) Student's knowledge, the information about the knowledge levels of students. There are two approaches that can be used, namely: the test automatically (auto-evaluation) by an adaptive system and the test manual (manual- evaluation) by a teacher. Levels of knowledge students can be categories: new, beginner, medium, advance and expert.

3) Student's achievement, the information relate to student achievement results.

4) Student's preferences, which explain the concept of information preferences, such as: cognitive preferences: (introduction, content, exercise, etc.), preferences physical support (text, video, images, etc.).

\section{METHODOLOGY}

\section{A. Research setting and procedures}

The method used in this research is the development of research methods (research and development. Because the media developed in the research development will produce the final product in software simulation program, then software development method used is the System Development Life Cycle (SDLC) Model. SDLC method is a method of software development is structured.

\section{B. Adaptive Mobile Learning Concept}

Functional design/learning process flow of Adaptive Mobile Learning in this study looks at the figure 1.

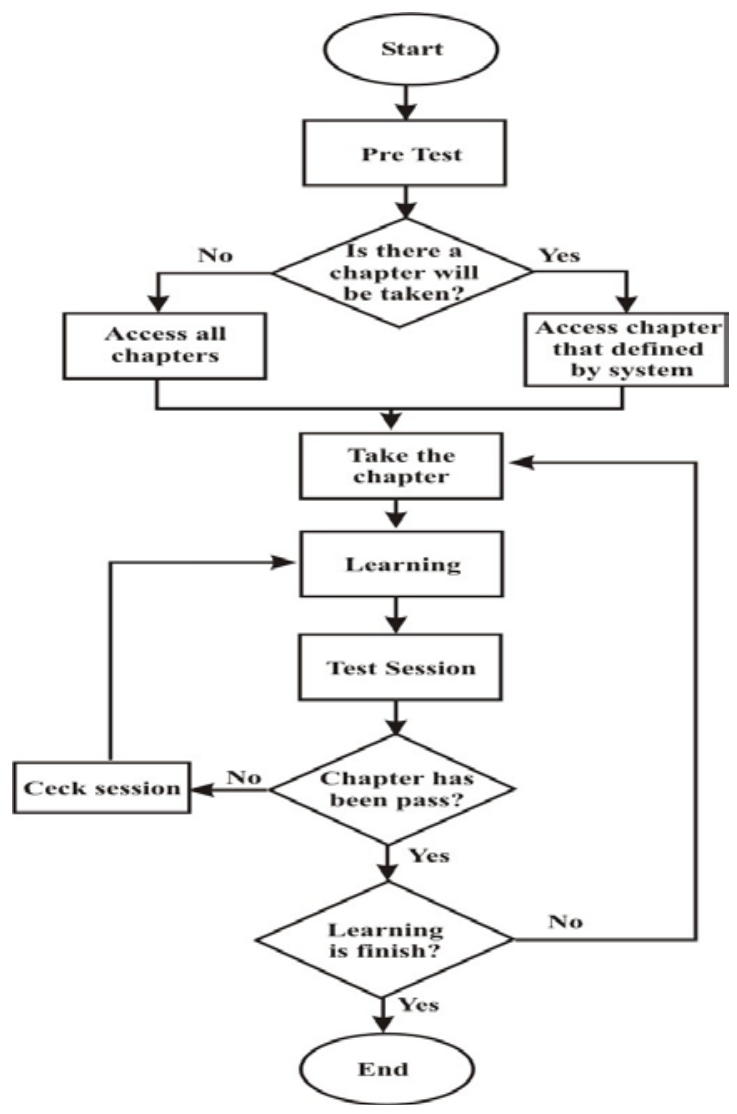

Fig. 1. Flow chart of Adaptive Mobile Learning [9]

The stages of the learning process adaptive mobile learning, as follows:

1) Perform pre-test trials on learners before doing the learning of a chapter (courses), learners will acquire a pre-test with the following provisions. 
a) Questions were taken representing each chapter. pre-test.

b) Teachers determine the questions selected for the

c) The results passed or not passed are determined by the percentage of the chapter of correct answers to the questions in each chapter, where the teacher determines the percentage of pass for each chap Questions are taken that represent each chapter.

d) The selection of question is determined through the analysis of test item such as content validity, item analysis and internal consistency of item and test.

e) Teacher determines number of questions for pre test.

f) Results of pass or not are determined by the percentage of chapter number of correct answers on the questions in each chapter, wherein teachers determine the percentage of pass for each chapter.

2) The purpose of the pre-test is to determine the ability of early learners. After testing the pre-test, the system will provide a chapter that can be accessed in accordance with the level of understanding of learners. Some possible after pretests conducted.

a) There is no chapter that pass

If all chapters do not pass, the learners may only access the lowest chapter that has not been passed.

\section{b) Some or all of the chapters pass}

If there are several chapters that pass, then only chapter passed that can be accessed. If all the chapters pass then all the chapters can be accessed.

3) Taking a chapter. There are two conditions in taking the matter:

a) The conditions in which learners are free to choose the material.

b) The conditions in which learners must take the material determined by the system. This happens because there are chapters that do not pass the pre-test.

4) Taking the test session. After the learning process, learners are required to take a test session. Provisions in the test session is as follows:

a) Questions used from chapters that have been taken.

b) Standard passing score is determined by the teacher

c) If learners do not take the test session, learners are not able to continue the learning process. chapter.

d) The results obtained are passed or not passed on each

There are several possibilities in this test session:

1) If learners do not pass the test session, the learners will repeat the learning process for the chapters that did not pass. Repetition of the learning process will be stored by the system as a learning session.

2) If learners pass, then learners can continue to the next chapter.
3) If all the chapters have been completed, learners can complete the learning process.

\section{Research Location}

The location study was conducted in the Department of Informatics Technology Education, Faculty of Engineering and Vocational, Ganesha Education of University.

\section{Variables}

The independent variable in this study is the tool of learning interaction on subjects Information Systems are used, namely by Adaptive Mobile Learning that was developed in this study. The dependent variable were measured in the study is a learners response in the Department of Informatics Technology Education are use of Adaptive Mobile Learning as a tool for learning interaction on subjects Information Systems.

\section{E. Samples/Subject of research}

This research was conducted at the Department of Informatics Technology Education. Which will be samples/subjects in this study were learners at the Department of Informatics Technology Education who took a course of Information Systems In the odd semester of academic year 2014/2015.

\section{F. Sampling Techniques}

In the odd semester of academic year 2014/2015, the number of learners that as many as 31 people ( 1 class) and own a smartphone. The data taken from this research is learners response using the Adaptive Mobile Learning as a tool (supplement) in the learning process in the subject of Information Systems.

\section{G. Data Analysis}

Learners responses were analyzed using a questionnaire with Likert scales of 5 (the value of 1 to 5) were analyzed descriptively. Conversion learners response rates can be seen in Table I below:

TABLE I. CONVERSION TABLES LIKERT SCALE LEARNERS RESPONSE [22]

\begin{tabular}{|c|c|}
\hline The range of values & Response categories \\
\hline $\mathrm{M}_{\mathrm{i}}+1,5 \mathrm{~S}_{\mathrm{i}} \leq \mathrm{x}$ & Very Positively \\
\hline $\mathrm{M}_{\mathrm{i}}+0,5 \mathrm{~S}_{\mathrm{i}} \leq \mathrm{x}<\mathrm{M}_{\mathrm{i}}+1,5 \mathrm{~S}_{\mathrm{i}}$ & Positive \\
\hline $\mathrm{M}_{\mathrm{i}}-0,5 \mathrm{~S}_{\mathrm{i}} \leq \mathrm{x}<\mathrm{M}_{\mathrm{i}}+0,5 \mathrm{~S}_{\mathrm{i}}$ & Hesitant \\
\hline $\mathrm{M}_{\mathrm{i}}-1,5 \mathrm{~S}_{\mathrm{i}} \leq \mathrm{x}<\mathrm{M}_{\mathrm{i}}-0,5 \mathrm{~S}_{\mathrm{i}}$ & Negative \\
\hline $\mathrm{X}<\mathrm{M}_{\mathrm{i}}-1,5 \mathrm{~S}_{\mathrm{i}}$ & very negative \\
\hline
\end{tabular}

\section{H. Criteria for the success of this research}

Development and the use of Adaptive Mobile Learning as interaction tools Information Systems course is considered successful if it meets the criteria of the research are: 1) The presence of Adaptive Mobile Learning as a tool in teaching Information Systems. 2) Learners response in the Department of Informatics Technology Education to use of Adaptive Mobile Learning as a tool for learning interaction Information Systems achieve positive category or more 


\section{RESUlts}

\section{A. System Implementation}

This research is the development of Adaptive Mobile Learning is applied to the Information Systems course. This research was conducted for 8 months starting from March to October. Here are excerpts of the program that has been developed.

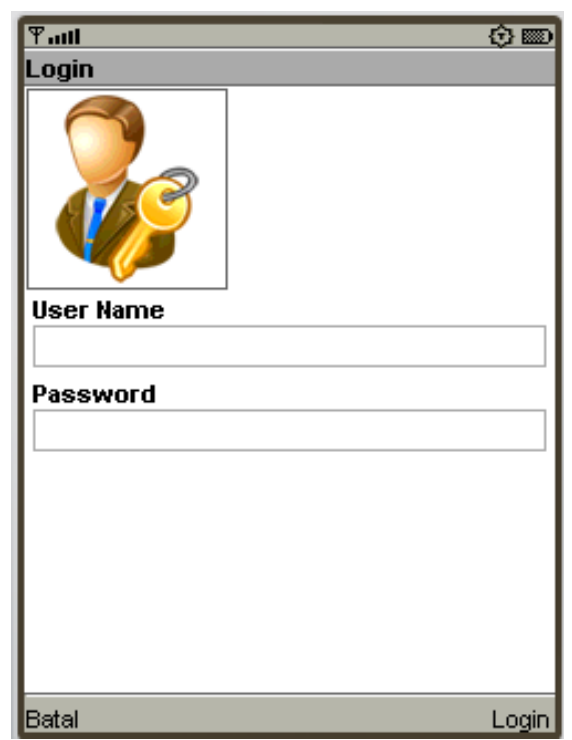

Fig. 2. Login form

This form is used by the learner to the login process. Login process using username (Student ID Number) and password.

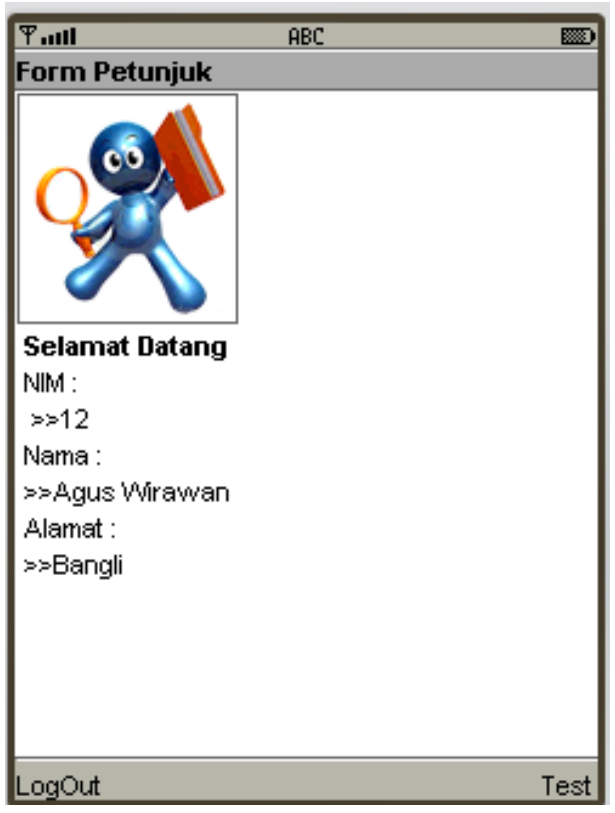

Fig. 3. Main form

The main form displays information of learners who successfully login. Information such as identification numbers, names and addresses. In the main form, learners can perform the logout process or Test. Test button was used to measure the ability of learners before the learning process begins.

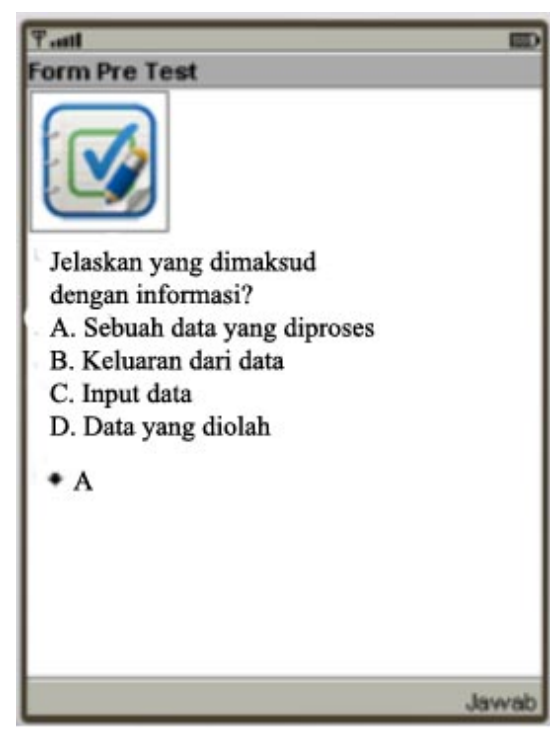

Fig. 4. Pre test form

Form pre-test is used to measure the initial capabilities of learners. There are several provisions in the pre-test processes such as:

1) The questions are presented is the early material of each chapter.

2) The teacher can determine the number or type of questions selected for the pre-test.

3) The results passed or not is determined by the percentage of the number of chapters of the correct answers to the questions in each chapter, where the teacher determines the percentage of pass for each chapter.

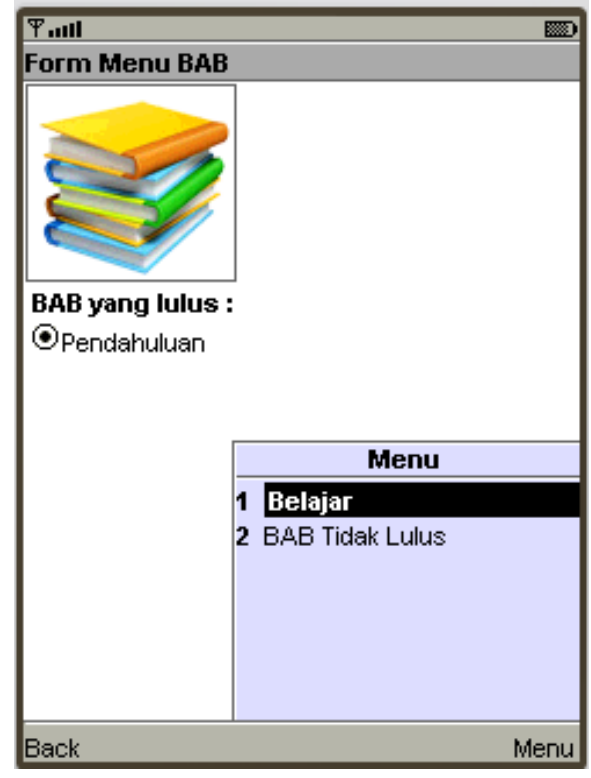

Fig. 5. Chapter form

This form is used to display the chapter material that pass or not pass from the pre test. This form is used to display the chapter material that pass or not pass from the pretest. There are two conditions in the learning process: 

freely

1) The learner can access the chapter that has passed

2) learners can access the chapter which does not pass (pre-test) in accordance with the directives of the system.

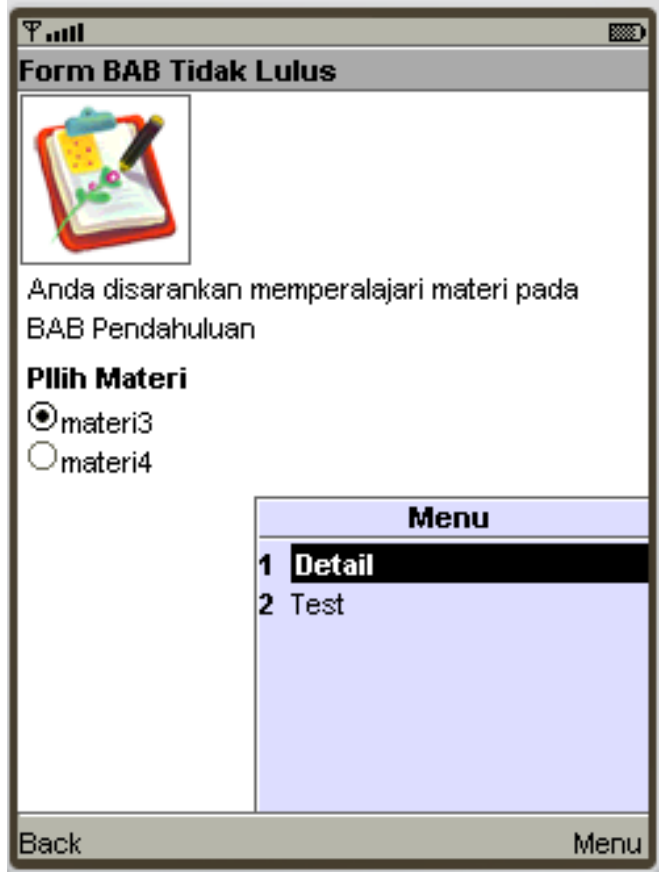

Fig. 6. Content form

This form are used to display the detail of material of each chapter.

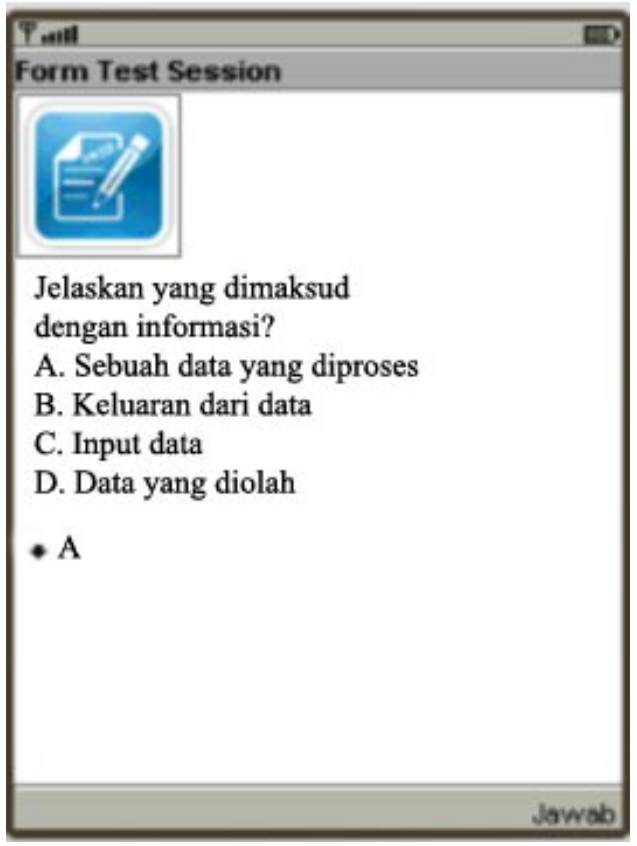

Fig. 7. Test session form

This form is used to display the questions of the test session

\section{B. System testing process}

In this study conducted three testing phases, namely:

1) Technical testing, the test was conducted by researchers themselves to functional test of software (Black box testing) and examine the structure of software algorithms (White box testing).

2) Software testing as a medium of learning, carried out through expert review content, and media experts.

3) Field testing process, testing is given to learners in Department of Informatics Technology Education, who took a course on Information Systems. Results of learners response that consists of a 10-point declaration was measured with a Likert scale of 1-5. Ideal highest score and the lowest score is the ideal respectively 50 and 10 . The calculation of the mean and standard deviation are as follows.:

The mean of ideal $=1 / 2$ (highest score ideal + lowest score ideal)

$$
\begin{aligned}
& =1 / 2(50+10) \\
& =30
\end{aligned}
$$

Deviation standard of ideal $=1 / 6$ (highest score ideal lowest score ideal)

$$
=1 / 6(50-10)
$$$$
=6,7
$$

Response categories of students who use Adaptive Mobile Learning in Information Systems courses shows that students that learned responses Adaptive Mobile Learning in Information Systems course is very positive for $67.7 \%$ and $32.3 \%$ positive. It can be concluded that the response of the learners tend to be very positive.

\section{Discussion}

At this stage of the software development using J2ME programming language and MySQL database. For the connection between mobile phone with a database requires server using the PHP language. Utilization of mobile devices on the learning process of Information Systems can be done anywhere and anytime. Besides, the process of learning can be adjust the level of ability of the students, this is because the concept of adaptive learning.

At the time limited testing in a class, to determine the response of students to use the software in Information Systems course, visible a very positive response who use Adaptive Mobile Learning. With the very positive response from the students on the course Information System using Adaptive Mobile Learning software, it is hoped able to increase the level of student ability of Information Systems, and is expected to improve student-learning outcomes. For this year, the research was conducted only the software development and limited testing to determine the response of students using Adaptive Mobile Learning.

\section{CONCLUSIONS AND FUTURE WORK}

Based on this research, suggestions is can be presented as:

1) The design of Adaptive Mobile Learning can model of Information System material. 
2) Implementation of Adaptive Mobile Learning software can present material of information system and as an alternative media in the process of learning materials of information system anywhere and anytime.

3) The student response to the development and use of Adaptive Mobile Learning software for learning Information System is very positive, with $67.7 \%$ is very positive, and $32.3 \%$ is positive.

Based on this research, suggestions is can be presented as follows:

1) Need more mobile learning media to help students in the learning process anywhere and anytime and supports the concept of go green campus.

2) For further research can continue the experimental study of this study, so that the learning outcomes of the use of Adaptive Mobile Learning of Information Systems can be known.

3) For further research can be combined with adaptive learning models so that the learning process will be more interactive.

\section{ACKNOWLEDGMENT}

The authors express their gratitude to the faculty, staff and students of Department of Information Technology Education, Faculty of Technical and Vocational Education Ganesha University who has helped and supported the implementation of this research, especially on the data of student responses.

\section{REFERENCES}

[1] Khan. B, "Managing E-Learning Strategies: Design, Delivery, Implementation and Evaluation”, Hershey, PA, USA: Idea Group Inc, 2001.

[2] Meister. J, Pillars of e-learning success, New York, USA: Corporate University Exchange, 2002.

[3] Frankola. K, Why online learners dropout. Workforce, 10, 53-63, 2001.

[4] Hernawati. K., "E-Learning Adaptif Berbasis Karakteristik Peserta Didik”, Prosiding Seminar Nasional Penelitian, Pendidikan dan Penerapan MIPA, Fakultas MIPA, Universitas Negeri Yogyakarta, 14 Mei 2011, ISBN: 978-979-99314-5-0, 2011.

[5] Sfenrianto, "A Model Of Adaptive E-Learning SystemBased On Student's Motivation", Proceedings International Conference on Creative Communication and Inovative Technology (ICCIT), 8 Agustus 2009, Tanggerang-Indonesia , ISSN 1978-8282, 2009.

[6] Surjono. H. D, "Pemanfaatan Teknologi E-Learning Adaptif untuk Mengatasi Keragaman Gaya Belajar”, Jurnal Penelitian Saintek, Vol 8, No 1, April 2013.

[7] Dantes. G. R, Suarni. N. K and Sujaya. I. G, "Model Dynamic Intellectual Learning (DIL): Pergeseran Paradigma E-Learning Menuju Adaptive Learning”, Konferensi Nasional Sistem dan Informatika 2010; Bali, November 13, 2010

[8] Esichaikul. V, Lamnoi. S and Bechter. C, "Student Modelling in Adaptive E-Learning Systems”, Knowledge Management \& E-Learning: An International Journal, Vol.3, No.3, 2011.

[9] Wirawan. I. M. A and Wahyuni. D. S, "Adaptive Mobile Learning Concept", Proceedings of the International Mobile Learning Festival, Bali - Indonesia June 2 - 4, 2014.
[10] C. A. Carver, R. A. Howard and E. Lavelle, "Enhancing student learning by incorporating learning styles int o adaptive hypermedia", Proceedings of ED-MEDIA '96 World Conf. on Educational Multimedia and Hyper media, (1996) June, 17-22, Boston, USA.

[11] J. E. Gilbert and C. Y. Han, "Adapting instruction in search of a significant difference”, Journal of Network a nd Computer Applications, vol. 22, (1999), pp. 1-12.

[12] M. Stern and P. Woolf, "Adaptive content in an online lecture system”, Proceedings of the International Conf erence on Adaptive Hypermedia and Adaptive Web based System, (2000) August 28-30, Trento, Italy, pp. 29 1-300.

[13] M. Grigoriadou, K. Papanikolaou, H. Kornilakis and G. Magoulas, "INSPIRE: An intelligent system for personalized instruction in a remote environment", Proceedings of 3rd Workshop on Adaptive Hypertext and Hypermedia, (2001) July 13-17, Sonthofen, Germany, pp. 13-24.

[14] P. Paredes, and P. Rodrigues, "Considering sensing-intuitive dimension to exposition-exemplification in ada ptive sequencing", Proceedings of AH2002 Workshop, Second International Conference on Adaptive Hyper media and Adaptive Web-based Systems, (2002) May 29-31, Malaga, Spain, pp. 556-559.

[15] N. Stash, A. Cristea and P. D. Bra, "Authoring of learning styles in adaptive hypermedia: problems and solutions", Proceedings of the WWW 2004 Conference, (2004) May 17-22, New York, USA, pp. 114123.

[16] J. Lee, “Adaptive Courseware Using Kolb's Learning Style”, International Magazine on Advances in Comput er Science and Telecommunication, vol. 3, no. 1, (2012), pp. 45-59.

[17] G. K. Tallmadge and J. W. Shearer, "Study of Training Equipment and Individual Differences: the Effects of Subject Matter Variables", Supplementary Report, American Institutes for Research, (1968).

[18] D .C. Berliner and L. S. Cahen, "Trait-Treatment Interaction and Learning”, Review of Research in Education, vol. 1, (1973), pp. 58-94.

[19] D. H. Jonassen, "Aptitude-versus content-treatment interactions, implication for instructional designs", Journal of Instructional Development, vol. 5, no. 4, (1982), pp. 15-27.

[20] Wirawan, "Development Learning Media for Mobile Phone Based Materials Basic SQL Syntax in Subjects Advanced Database (Case Study on IT Educational Programs Semester III)”, Prosiding Seminar Internasional Teknologi Informasi dan Pendidikan, Bridging ICT and Education, ISSN 1907-3739,DIN EN ISO 9001:2008,Cert. No.01 100 086042, Fakultas Teknik Universitas Negeri Padang, 2011.

[21] Qing L, Shaochun Z, Peng W, Xiaozhuo G, and Xiaolin Q, "Learner Model in Adaptive Learning System", Journal of Information \& Computational Science 7: 5 (2010) 1137-1145

[22] Sugiono, Metode Penelitian Kuantitatif, Kualitatif dan R \& D, Alfabeta, Bandung, 2012.

\section{Author PROFILE}

I Made Agus Wirawan, S.Kom., M.Cs he is a lecturer in

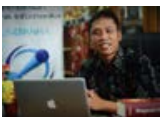
Ganesha University of Education. He earned her Master degree from Gadjah Mada University. Her research interests include artificial intelligence, adaptive learning, case based reasoning, and mobile phone technology. He has published papers in International Journal of Computer Applications, Journal of Educational Development Research, and National journal of information engineering education and among others.

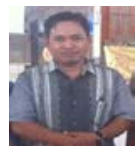

Made Santo Gintakarna, S.T., M.T he is a lecturer in Ganesha University of Education. He earned her Master degree from ITS. Her research interests include artificial intelligence, Elearning, and robotic. 